\title{
Prevalence and etiologies of visual handicaps in leprosy patients in the south of Cameroon
}

\author{
André Omgbwa Eballél \\ Didier Owono ${ }^{2}$ \\ Alphonse Um Book ${ }^{2}$ \\ Assumpta Lucienne Bella ${ }^{2}$ \\ Come Ebana Mrogo ${ }^{2}$ \\ Nsom $\mathrm{Mba}^{3}$ \\ 'Faculty of Medicine and Pharmaceutical \\ Sciences, University of Douala, Douala, \\ Cameroon; ${ }^{2}$ Faculty of Medicine \\ and Biomedical Sciences, University \\ of Yaoundé I, Yaoundé, Cameroon; \\ ${ }^{3}$ National Programme for Leprosy \\ Control, Ministry of Public Health, \\ Yaoundé, Cameroon
}

Correspondence: André Omgbwa Eballé Ophthalmology Unit, Gynaeco Obstetric and Paediatric Hospital of Yaoundé, PO BOX 4362, Yaoundé, Cameroon Tel +23799654468

$\mathrm{Fax}+23722212430$

Email andyeballe@yahoo.fr

\begin{abstract}
We report on a prospective study undertaken in April 2008, in 11 leper villages of the Southern Cameroon. Our aim was to determine the prevalence and the causes of bilateral blindness, low vision and unilateral blindness in the population of leprosy patients, irrespective of the clinical aspects of the illness.

Results: Two hundred thirty-five known and newly diagnosed leprosy patients were examined. These patients included 149 cases (63.4\%) of multibacillary leprosy and 86 cases $(36.6 \%)$ of paucibacillary leprosy. There were 111 case of visual handicap, representing $47.2 \%$ of the population. These visual handicap cases were subdivided into 45 cases (19\%) of bilateral blindness, 35 cases (15\%) of unilateral blindness and 31 cases $(13.2 \%)$ of low vision.

Discussion: The prevalence of visual handicap among leprosy patients in Cameroon is too high. Causes in the majority of cases are age-related degenerative pathologies, and one third of cases are linked to the leprosy mycobacterium.

Conclusion: Discovering a cure for ophthalmic pathologies is important in order to provide a better quality of life for this particular population.

Keywords: leprosy, eye, blindness, Cameroon

\section{Introduction}

Leprosy is caused by a resistant acid-fast bacillus, Mycobacterium leprae, isolated in 1873 by the Norwegian doctor, Hansen. The bacillus is transmitted among humans, who are the sole reservoirs of the bacillus. ${ }^{1}$ This scourge is considered an old companion, and the effects suffered by humanity include mutilation, disfigurement and blindness. In African and Asian literature, we find high rates of visual handicap in the population of leprosy patients. ${ }^{2-5}$ No data are available on the prevalence and causes of visual handicap in those affected by leprosy in Cameroon. Our aim was to determine the prevalence and causes of bilateral blindness, low vision and unilateral blindness in the leper population, irrespective of the clinical forms of the disease.
\end{abstract}

\section{Methodology}

This prospective and descriptive study was conducted from April 1st to 31st, 2008, in four regions of Cameroon: the centre, south, west and littoral regions, which comprise 11 leper villages (Ayos, Mbalmayo, Nyamsong, Ngallan-Ebolowa, Mvoutessi, Sangmelima, Nkonmelen, Baleng, Koutaba, Ombessa and Dibamba). The medical team comprised an ophthalmologist, an ophthalmic nurse, and two nurses who specialized in leprosy.

After we had obtained their consent, patients were regrouped in their leper villages, interviewed, and given a complete ophthalmologic examination (distant visual acuity using the Snellen chart, and near visual acuity according to the Parinaud scale; biomicroscopy; gonioscopy with a Goldmann three mirror lens, direct ophthalmoscopy and measuring of the intraocular pressure using a tonopen). Corneal sensation was tested by approaching the eye from the side with a piece of cotton-wool while the patient 
was looking straight ahead. Old and new patients undergoing or at the end of their treatment were included.

The World Health Organization (WHO) classification (or staging) of blindness and low vision was used.

- Bilateral blindness is defined as visual acuity of less than $3 / 60(1 / 20)$ from the corrected better eye.

- Low vision is defined as visual acuity of less than $6 / 18$ $(3 / 10)$, but equal or superior to $3 / 60(1 / 20)$ for the better eye with better correction.

We considered a patient to be unilaterally blind, when visual acuity of the better eye was superior or equal to $6 / 18$ $(3 / 10)$, and the other eye had visual acuity of less than $3 / 60$ (1/20) with better correction.

We used the Epi Info 6.04 programme to analyze the different variables (sex, age, clinical form, treatment, past history, bilateral blindness, unilateral blindness, low vision). The correlation was statistically significant when the test was inferior to 0.05 .

\section{Results}

Two hundred thirty-five leprosy patients (old and new), living in the 11 leper villages cited above were examined, including 118 males (50.2\%) and 117 females (49.8\%) (Table 1). Their ages ranged from 9 to 99 years with a mean age of $65.32 \pm$ 13.15 years; the age most represented was that above 60 years (174 patients; $77 \%) .149$ patients $(63.4 \%)$ had multibacillary leprosy, and $86(36.6 \%)$ had paucibacillary leprosy. Leprosy in 231 patients $(98.3 \%)$ had healed; two cases of relapse and two new cases were still undergoing treatment. The treatment commonly received was monochemotherapy with Dapsone $92.8 \%$, while $7.2 \%$ had received polychemotherapy. Some current general pathologies we found included 12 cases of high blood pressure and one diabetic type II patient.

Two patients had had cataract surgery. The main ophthalmic complaint was decrease of visual acuity (89.8\%). According to far visual acuity with the better correction, we counted 111 visual handicaps (61 males and 50 females), which is $47.2 \%$ of the total study population. There were 77 cases of multibacillary leprosy and 34 cases of paucibacillary leprosy, and 45 cases of binocular blindness (19\%), 35 cases of monocular blindness (15\%), and 31 cases of low vision (13.2\%).

Out of the 470 eyes examined, $270(57.4 \%)$ presented some lesions. The most common ocular lesions seen were cataract in 135 eyes (28.7\%), age-related macular degeneration (ARMD) in 44 eyes (9.3\%), glaucoma in 37 eyes $(7.9 \%)$ and phthisis bulbi in 26 eyes (5.5\%) (Table 4). Out of the 135 cases of cataract, six were secondary cataracts due to chronic uveitis.
Table I Age and sex distributions

\begin{tabular}{|c|c|c|c|c|}
\hline \multirow{3}{*}{ Age (years) } & \multicolumn{2}{|c|}{$\mathbf{N}=\mathbf{2 3 5}$} & \multicolumn{2}{|c|}{$\mathbf{N}=|\mathbf{I}|$} \\
\hline & \multicolumn{2}{|c|}{ Leprosy patients } & \multicolumn{2}{|c|}{ Handicaps } \\
\hline & Male & Female & Male & Female \\
\hline $0-19$ & 2 & 2 & 1 & 0 \\
\hline $20-39$ & 3 & 2 & 1 & I \\
\hline $40-59$ & 28 & 24 & 9 & 6 \\
\hline $60+$ & 85 & 89 & 50 & 43 \\
\hline Total & 118 & 117 & 61 & 50 \\
\hline
\end{tabular}

The leading adnexae lesions were madarosis and alopecia (66 cases) (28\%), followed by ectropion in 12 cases $(5.1 \%)$, lagophtalmia due to seventh nerve palsy in 10 cases $(4.2 \%)$ and corneal anesthesia 10 cases $(4.2 \%)$.

The main causes of visual handicap were phthisis bulbi and cataract for unilateral blindness; cataract, glaucoma and phthisis bulbi for bilateral blindness; and cataract, ARMD and glaucoma for low vision (Table 2). No trachoma lesions were found in these patients. In the endemic area of onchocerciasis, we found four eyes blinded by onchocerciasis retinitis.

Visual handicap supposedly due to leprosy (phthisis bulbi, corneal opacity, secondary cataract, secondary glaucoma, and acute iridocyclitis) was observed in 55 eyes of 39 patients $(35 \%)$ in the 111 handicap cases (Table 3$)$.

\section{Discussion}

A statistically insignificant slight male predominance was observed $(\mathrm{p}=0.94)$. This male predominance in a population of lepers has been shown in many recent studies. ${ }^{2,6,7}$ The population in our series is aging, with an average of 65 years; this aging has already been described by Mvogo

Table 2 Causes of visual handicaps

\begin{tabular}{llll}
\hline Pathologies & $\begin{array}{l}\text { Unilateral } \\
\text { blindness }\end{array}$ & $\begin{array}{l}\text { Bilateral } \\
\text { blindness }\end{array}$ & Low vision \\
\hline Cataract & $10(28.6 \%)$ & $19(42.2 \%)$ & $15(48.4 \%)$ \\
Glaucoma & $4(11.4 \%)$ & $10(22.2 \%)$ & $4(13 \%)$ \\
Phthisis bulbi & $12(34.3 \%)$ & $7(15.6 \%)$ & - \\
ARMD & - & $4(8.9 \%)$ & $7(22.6 \%)$ \\
Corneal opacities & $6(17.1 \%)$ & $3(6.7 \%)$ & $2(6.4 \%)$ \\
Onchocerciasis & - & $2(4.4 \%)$ & - \\
retinitis & & & - \\
Macular hole & $2(5.7 \%)$ & - & $\mathrm{I}(3.2 \%)$ \\
Panuveitis & $\mathrm{I}(2.8 \%)$ & - & $\mathrm{I}(3.2 \%)$ \\
Bilateral aphakia & - & - & $\mathrm{I}(3.2 \%)$ \\
Optic neuropathy & - & - & $3 \mathrm{I}(\mathrm{I00} \%)$ \\
Total & $\mathbf{3 5 ( 1 0 0 \% )}$ & $\mathbf{4 5}(\mathbf{1 0 0 \% )}$ & \\
\hline
\end{tabular}


Table 3 Pathologies linked to leprosy as causes of visual handicaps

\begin{tabular}{lll}
\hline Pathologies & $\begin{array}{l}\text { Number } \\
\text { of eyes }\end{array}$ & $\%$ \\
\hline Phthisis bulbi & 26 & 47.3 \\
Corneal opacities & 14 & 25.4 \\
Secondary cataract & 6 & $1 \mathrm{I}$ \\
Secondary glaucoma & 4 & 7.3 \\
Optic neuropathy & 3 & 5.4 \\
Panuveitis & 2 & 3.6 \\
Total & $\mathbf{5 5}$ & $\mathbf{1 0 0}$ \\
\hline
\end{tabular}

Note: Fifty-five eyes for 39 patients.

and colleagues ${ }^{7}$ who found a mean age of 59.4 years in the same region of Cameroon. Yet this advanced age is quite comprehensible. Lepers receive assistance from nongovernmental organizations, and also benefit from the National Programme for leprosy control, managed by the Cameroon Ministry of Public Health. Ministry statistics reveal that the disease may even be eradicated in Cameroon, with a prevalence of 0.26 per ten thousand in $2007 .{ }^{8}$

This study supports the finding $(\mathrm{p}=0.00006)$ of many studies which have identified multibacillary leprosy as being the most frequent clinical form. ${ }^{2,8-12}$ Mvogo and colleagues, ${ }^{7}$ however, found that paucibacillary leprosy was the most frequent form.

\section{Ocular findings}

Cataract was the most frequent intraocular lesion. This finding is explained by the aging of the population of lepers, who

Table 4 Ocular pathologies

\begin{tabular}{llll}
\hline Pathologies & $\begin{array}{l}\text { Multibacillary } \\
\text { leprosy }\end{array}$ & $\begin{array}{l}\text { Paucibacillary } \\
\text { leprosy }\end{array}$ & Total eyes \\
\hline Cataract & 95 & 39 & 135 \\
ARMD & 26 & 18 & 44 \\
Glaucoma & 25 & 12 & 37 \\
Phthisis bulbi & 20 & 6 & 26 \\
Corneal opacities & 12 & 3 & 15 \\
Aphakia & 2 & 2 & 4 \\
Onchocerciasis & 2 & 2 & 4 \\
retinitis & & 1 & 3 \\
Active keratitis & 2 & 1 & 2 \\
Active uveitis & 1 & 2 & 3 \\
Optic neuropathy & 1 & - & 270 \\
Macular hole & 2 & $\mathbf{8 5}$ & 2 \\
Total & 186 & & \\
\hline
\end{tabular}

Abbreviation: ARMD, age-related macular degeneration. Note: Two hundred eyes over 470 were normal. develop degenerative pathologies later in life. This hypothesis is supported by the results of Mpyet and colleagues, ${ }^{2}$ who showed that cataract was the main ocular pathology. Corneal opacities and cataract were the leading ocular pathologies in the study by Mvogo and colleagues. ${ }^{7}$ Madarosis and alopecia were the leading adnexal lesions, as already described. ${ }^{7}$

The prevalence of visual handicap in this population is very high, which is a result of the absence of ophthalmic care of these patients who are confined in their leper villages. The rates of bilateral blindness and low vision are 4 to 10 times higher than the rate in the general population: as estimated by WHO in 1997 , at $1.4 \%$ for bilateral blindness and $4.5 \%$ for low vision. ${ }^{13}$ In other developing countries, the rate of visual handicap is slightly lower, for example, $8.7 \%$ of bilateral blindness in northeastern Nigeria, ${ }^{3}$ and $7.7 \%$ of bilateral blindness in China. ${ }^{4}$ The prevalence of unilateral blindness in our study was $15 \%$, which we consider a very high rate compared with the $4.4 \%$ observed in China. ${ }^{4}$ The prevalence of low vision was $13.2 \%$, not too far from the Chinese rate of $9.28 \%,{ }^{4}$ as opposed to the low prevalence of $4.4 \%$ found in Uganda. ${ }^{14}$

Cataract was the main cause of low vision in our study, similar to that observed in Nigeria and China;,4 followed by ARMD and glaucoma. These conditions are mainly age-related degenerative pathologies, and are common in both aging lepers and normal people. Corneal opacities and optic neuropathies of the 4th and 5th positions could result from leprosy.

According to WHO in $1997,{ }^{15}$ the leading causes of bilateral blindness in sub-Saharan Africa are cataract, trachoma, and glaucoma. This study supported this finding for cataract and glaucoma. Hogeweg and colleagues ${ }^{16}$ showed that age-related cataract has become the leading cause of blindness in the leprosy population, contrary to the finding of Yang and colleagues ${ }^{5}$ that leucoma and corneal ulcers are the main causes of blindness in lepers. The provision of an adequate cataract surgical service could nearly halve the burden of blindness in this population. Phthisis bulbi and corneal opacities, taking the $3 \mathrm{rd}$ and the 5 th positions of bilateral blindness, are also most important causes of unilateral blindness, which could be the result of exposure to keratitis, induced by lagophtalmia from seventh nerve palsy linked to leprosy. ARMD was the 4th cause of bilateral blindness in this population of lepers, whose average age was 65 years.

In total, out of 111 patients with visual handicaps, 39 cases (35\%) were due to leprosy, thus confirming the results of Mpyet and colleagues ${ }^{2}$ from northeastern Nigeria, who found that one third of blindness is linked to leprosy in this population. 


\section{Conclusion}

The prevalence of visual handicaps in the population of lepers in southern Cameroon is very high. The main causes are age-related degenerative pathologies; one third of the cases are due to leprosy. Leprosy is considered a major problem, because low vision and blindness constitute other serious problems affecting the quality of life. There is an urgent need for ophthalmic care to reduce the prevalence of visual handicaps in these particular patients; such care may increase their chance of social and economic rehabilitation.

\section{Disclosure}

The authors report no conflicts of interest in this work.

\section{References}

1. Vedy J, Graveline J, Queguiner P, Auzemery A. Precis d'ophtalmologie tropicale. 2nd Ed. Marseille, France: Diffusion Générale de Librairie, Publisher; 1988.

2. Mpyet C, Solomon AW. Prevalence and causes of blindness and low vision in leprosy villages of north eastern Nigeria. $\mathrm{Br} J$ Ophthalmol. 2005;89:787.

3. Nwosu SN, Nwosu MC. Ocular findings in leprosy patients in Nigeria. East Afr Med J. 1994;71:441-444.
4. Yan L, Zhang G, Li W, et al. A survey of blindness and poor vision in leprosy patients. Chin Med J. 2003;116:682-684.

5. Yang J, Jian D, Hu L, et al. Blindness and low vision in leprosy patients in Sichuan Province, China. Indian J Lepr, 1998;70:139-143.

6. Waziri-Erameh MJ, Omoti AE. Ocular leprosy in Nigeria: a survey of an Eku leprosorium. Trop Doct. 2006;36:27-28.

7. Mvogo CE, Bella-Hiag AL, Ellong A, Achu JH, Nkeng PF. Ocular complications of leprosy in Cameroon. Acta Ophthalmol Scand. 2001;79:31-33.

8. Ministère de la Santé Publique. Programme national de Lutte contre la Lèpre. Bilan annuel. Yaoundé, Cameroon: Ministère de la Santé Publique, 2007.

9. Shields JA, Waring GO, Monte LG. Ocular findings in leprosy, Natal, Rio Grande de Norte, Brazil. Am J Ophthalmol. 1974;77:880-890.

10. Spaides R, Natis R, Lipka A, et al. Ocular findings in leprosy in the United States. Am J Ophthalmol. 1985;100:411-416.

11. Chams H, Sadeghy-Tari A, Farokh D, et al. La lèpre en Iran. Ophtalmologie. 1993;7:80-82.

12. Wade A, Ndiaye MR, Balo KP, Ceccon JF. Oeil et lepre. Méd Afr Noire. 1985;32:7.

13. OMS/Aide Memorie. La cécité et la déficience visuelle, partie I: informations générales. Aide mémoire; 1997. n 142.

14. Wadell KM, Saunderson PR. Is leprosy blindness avoidable? The effect of disease type, duration, and treatment on eye damage from leprosy in Uganda. Br J Ophthalmol. 1995;79:250-256.

15. OMS/Aide Memoire. Cécité et déficience visuelle, partie II: principales causes dans le monde. Aide Mémoire; 1997. nº 143.

16. Hogeweg M, Keunen JE. Prevention of Blindness in leprosy and the role of the vision 2020 programme. Eye. 2005;19:1099-1105. 